\title{
A 3 YEAR RECORD OF SEASONAL VARIATIONS IN SURFACE VELOCITY, STORGLACIÄREN, SWEDEN
}

\author{
By Roger leB. Hooke,* Peter Calla, Per Holmlund, mats Nilsson, and Arjen Stroeven
}

(Naturgeografiska Institutionen, Stockholms Universitet, S-106 91 Stockholm, Sweden)

ABstract. Between 3 June 1982 and 8 July 1985, a stake net consisting of up to 32 stakes covering the greater part of Storglaciären was surveyed 70 times, yielding roughly 2000 separate determinations of vertical and horizontal velocity. The time interval between surveys averaged about 1 week during the summer and 2 months during the winter.

Horizontal velocities were normally highest during periods of high daily temperature or heavy rain early in the melt season. Comparable or sometimes higher temperatures or rainfalls later in the season usually had less effect, though minor velocity peaks were of ten present in August and early September. During periods for which bore-hole water-level measurements are available, velocity peaks generally coincided with periods of high basal water pressure, but not all periods of high water pressure resulted in velocity peaks. Despite increasing basal water pressures, velocity decreased gradually during the winter.

Vertical velocities also vary seasonally. Beneath the upper part of the ablation area the glacier bed is overdeepened. Vertical velocities here are $\sim 3 \mathrm{~mm} / \mathrm{d}$ higher during the summer. Down-glacier from the overdeepening, vertical velocities are $\sim 1 \mathrm{~mm} / \mathrm{d}$ lower during the summer. These and other characteristics of the vertical velocity pattern are best explained by appealing to: (1) a decrease in strain-rate with depth, and (2) seasonal variations in this depth-dependence.

Five periods of high velocity lasting from 3 to $11 \mathrm{~d}$ were studied in detail. In an area where the bed is overdeepened, force-balance calculations suggest that basal drag decreased between 16 and $40 \%$ during these high-velocity events. This resulted in a decrease in compressive strain-rate at the up-glacier end of the overdeepening, an increase at the down-glacier end, and a slight increase in lateral shear strain-rates. Down-glacier from the overdeepening, basal drag increased during two events owing to an increased push from up-glacier and pull from down-glacier. Lateral shear strain-rates increased sharply here.

\section{INTRODUCTION}

Storglaciären (Fig. 1), a small sub-polar valley glacier in northern Sweden, is the principal glacier being studied by the Glaciology Division of the University of Stockholm's Department of Physical Geography. A wealth of data is available on the glacier including photographs from the turn of the century, a mass-balance record spanning over 40 years, maps of the surface at five different times since 1940 , a detailed map of the bed topography based on radio-echo surveys (Björnsson, 1981), and englacial temperature measurements to depths of up to $40 \mathrm{~m}$ in a

*Permanent address: Department of Geology and Geophysics, University of Minnesota, Minneapolis, Minnesota 55455, U.S.A. number of places (Schytt, 1966, 1968; Hooke and others, 1983a; unpublished data).

Recent work has concentrated on the role of water in the glacier's dynamics. Bore holes have been drilled to the glacier bed for measurement of internal deformation (Hooke and others, 1987; paper in preparation by V. Pohjola and R.LeB. Hooke) and water-pressure variations; water input to and discharge from the glacier have been monitored to determine storage (Östling and Hooke, 1986); the englacial water system has been studied through descents into moulins (Holmlund and Hooke, 1983) and annual mapping of remnant channel structures as they become exposed at the surface by ablation (Holmlund, 1988); the seasonal evolution of the englacial and subglacial water systems has been investigated using dye-trace techniques (Hooke and others, 1988; Seaberg and others, 1988); and detailed measurements of the variation of surface velocity in time and space have been carried out (Hooke and others, 1983b; unpublished data). The present paper focuses on the latter measurements, and particularly on data collected since the study reported in the 1983 paper.

Seasonal variations in surface velocity are known from a number of glaciers, and are usually attributed to variations in sliding speed caused by variations in water pressure in the subglacial channel system (see Hooke and others, 1983b; and references cited therein). Increases in water pressure are believed to increase the sliding speed both because they exert a direct down-glacier force on up-glacier-facing ice surfaces in cavities at the glacier bed (Iken, 1981), and because they promote separation of ice from the bed, thus increasing shear stresses in places where ice remains in contact with the bed (Kamb, 1970; Lliboutry, 1979; Iken and others, 1983). On glaciers resting on beds of unconsolidated material, increases in water pressure may weaken this material, allowing it to deform more readily (e.g. Clarke, 1987; and references therein).

In its lowermost third, Storglaciären probably rests on bedrock or non-deforming moraine. However, an electrical resistivity experiment conducted in 1986 (Brand and others, 1987 ) is interpreted as indicating that a layer of watersaturated till, $0.4-0.7 \mathrm{~m}$ thick, underlies the glacier just north of stake 2.45 (Fig. Ib). Tracer studies (Hooke and others, 1988; unpublished data of D.W. Wiberg) suggest that drainage is englacial rather than subglacial throughout the overdeepening between stakes 07 and 188, which further suggests that the till layer may extend beneath this entire area. Possibly, the layer deforms to fill and thus block incipient subglacial channels. Alternatively, and perhaps more likely, is the possibility that, for reasons as yet incompletely understood, drainage through such overdeepenings is commonly or always (?) englacial. The lack of subglacial drainage could therefore be responsible for the accumulation of till at the bed.

\section{PROCEDURE}

\section{Velocity measurements}

In May and June 1982, a network of 27 stakes was established on the glacier. Surveys of these stakes began on 


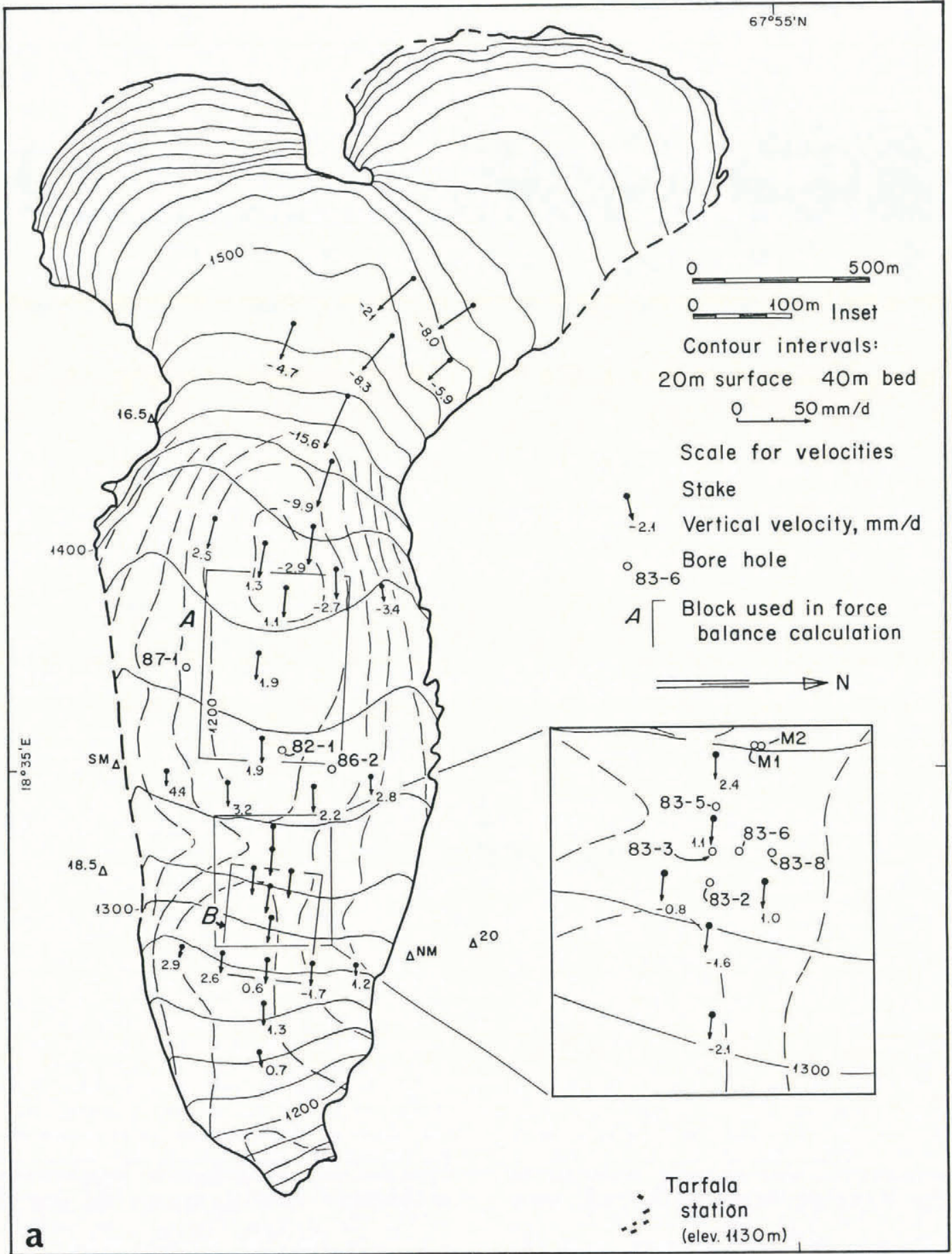

Fig. 1.a. Map of Storglaciären showing generalized surface and bed topography. Mean horizontal and vertical velocities of stakes are shown by arrows and numbers, respectively. $b$. Index map showing names of stakes in Figure 1a. See opposite.

3 June but the net was not completed until 23 June. This original net covered the greater part of the glacier; only the upper half of the accumulation area and the lowermost part of the ablation area were omitted in the interest of keeping the net small enough so that it could be surveyed by four people in one good day. In four places, up-glacier from stakes $02,1.35,188$, and 263 on Figure $1 \mathrm{~b}$, four stakes were set to form a roughly square strain diamond. In late March 1983, five additional stakes were added - the strain diamond up-glacier from stake 05 and the stake in the middle of the 02 diamond - in order to provide additional detail in an area where other experiments were in progress.

The $47 \mathrm{~mm}$ diameter stakes were initially $6 \mathrm{~m}$ long and were set in drill holes so that $\sim 0.5 \mathrm{~m}$ of the stake projected above the snow surface. As melting progressed, the stakes were cut. Then, when accumulation began in the autumn, extensions were added to keep the tops above the snow surface. Periodically, stakes melted out and had to be replaced. Ideally, the new stake was set and surveyed before the old one was lost, thus providing continuity. This ideal was not always achieved, so there are gaps in the record.

The stakes were normally surveyed at $7-10 \mathrm{~d}$ intervals from mid-May to mid-September, weather permitting, and at $45-90 \mathrm{~d}$ intervals during the remainder of the year. During a survey the coordinates of the tops of the stakes were determined by measuring distances to two of four fixed points (three of which $-16.5,18.5$, and $20-$ are shown in Figure la) using an AGA Geodimeter 12, and by measuring vertical angles to the stake tops from a third fixed point (either SM or NM; Fig. 1) with a Wild T-2 theodolite. The Geodimeter was placed directly on top of the stake and held in position by means of a short length of pipe that slid into or over the stake top. The reflecting prisms for the Geodimeter were permanently mounted on the fixed points. The Geodimeter measurements were 


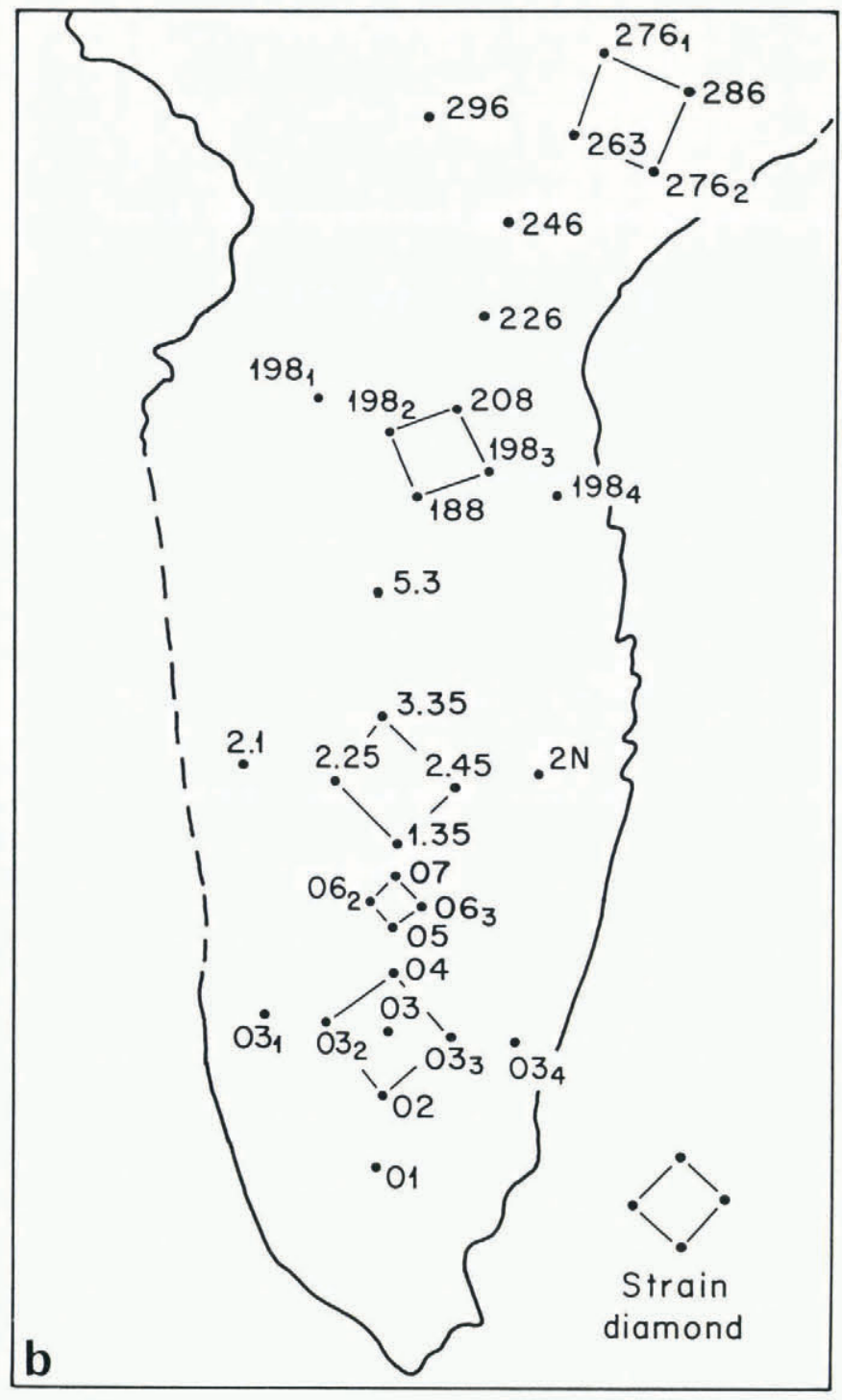

adjusted for atmospheric pressure and temperature effects with the use of meteorological data from nearby Tarfala Field Station (Fig. 1).

Because the fixed points used for vertical angle measurements were different from those on which prisms were mounted, an iterative procedure was necessary to establish stake coordinates. A vertical coordinate was assumed and used to calculate initial stake coordinates based on the measured slope distances. A revised vertical coordinate was then obtained with the use of the vertical angle. The calculation converges rapidly.

At intervals of several weeks, a Brunton compass was used to measure the inclinations of stakes to the nearest $10^{\prime}$ in two mutually perpendicular directions, parallel to the two axes of the net. Inclinations on the days of surveys were then obtained by linear interpolation or extrapolation. These measurements, together with the known length of the stake (including extensions), were used to determine the coordinates of the bottoms of the stakes. It was these coordinates that were used to calculate displacements and velocities. This procedure was adopted to accommodate changes in length of the stakes as they were cut or extended. All such changes in length were made in increments of $1.000 \pm 0.002 \mathrm{~m}$ to simplify calculations.

\section{Uncertainty in velocities}

The uncertainties in the velocity measurements are discussed in Appendix I. For surveys made $7 \mathrm{~d}$ apart, as attempted during the last two summers of the study, the uncertainties in coordinates result in standard errors in the horizontal and vertical velocities of $\pm 4.5 \mathrm{~mm} / \mathrm{d}$ and $\pm 1.5 \mathrm{~mm} / \mathrm{d}$, respectively, for the average stake and $\pm 7 \mathrm{~mm} / \mathrm{d}$ and $\pm 4 \mathrm{~mm} / \mathrm{d}$, respectively, for the most distant stakes. During the winter, when velocities were determined over periods of 6-10 weeks, the standard error is negligible.

By definition, some measurements will be in error by amounts substantially in excess of these estimates of the standard error. However, the overall consistency of the velocity variations among nearby stakes suggests that the large-scale pattern of velocity variation is correct, although some of the small-scale details may be due to measurement error.

\section{Water-pressure measurement}

Bore holes were drilled with a hot-water drill. We inferred that they had encountered the englacial or subglacial drainage system if the water level in the hole

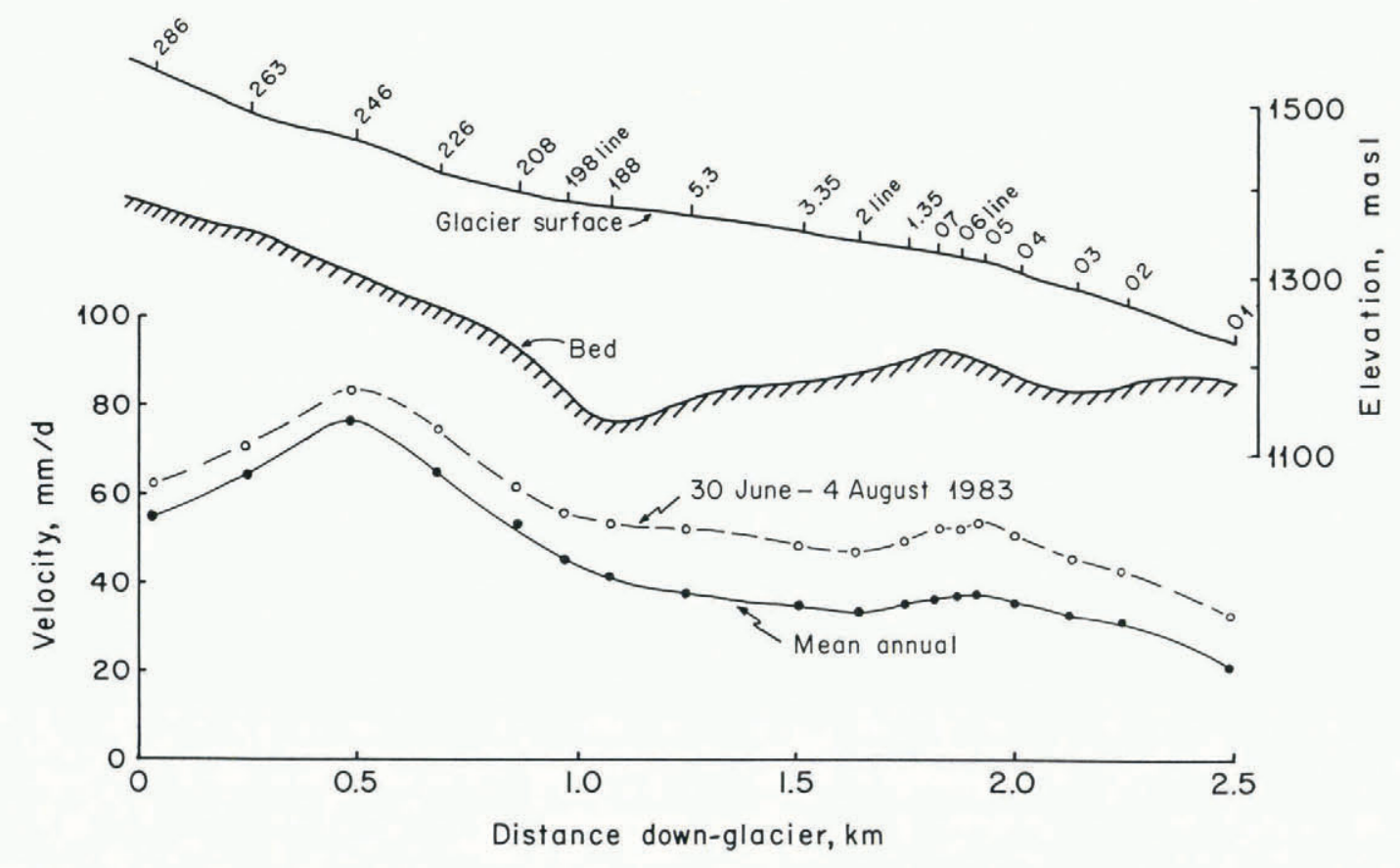

Fig. 2. Longitudinal variation in mean annual horizontal velocity, $u_{S}$, and in the mean velocity during July 1983. 

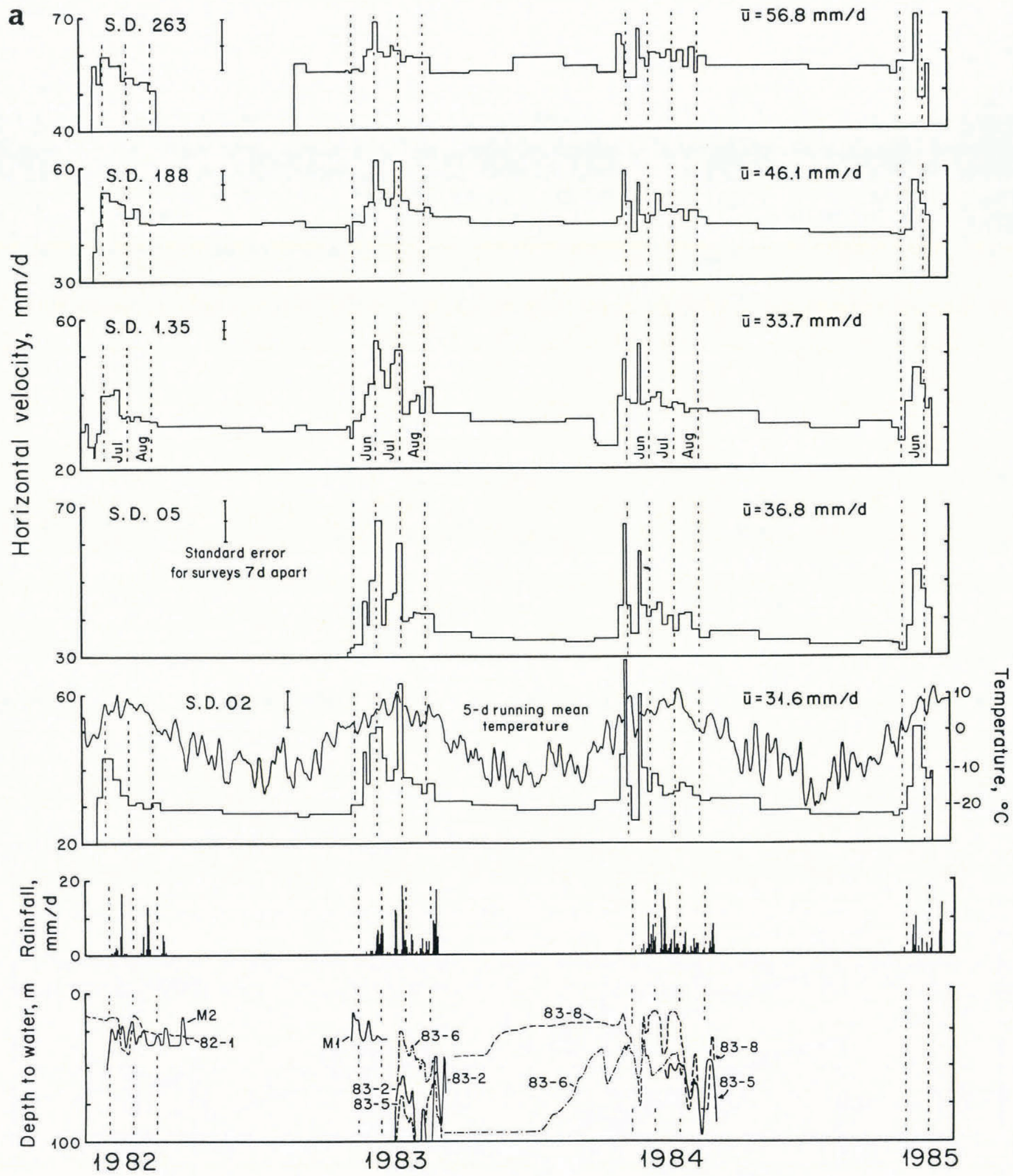

Fig. 3. a. Horizontal velocities of strain diamonds, obtained by averaging the velocities of the four (or five) stakes in the diamond. At the bottom are the mean daily temperature, smoothed using a $5 d$ running mean, daily rainfall, and maximum daily water pressures in moulins and bore holes. The latter are smoothed using a $5 d$ running mean. $b$. Vertical velocities of strain diamonds obtained by averaging the velocities of the four (or five) stakes in the diamond.

dropped well below the glacier surface during drilling and then began to oscillate diurnally. Pressure sensors, originally designed to measure oil pressure in automobile engines, were placed in these holes and connected to a chart recorder. Unless otherwise noted, there was no water flowing into the holes. Pressure sensors were also placed at depths of $35-40 \mathrm{~m}$ in some moulins.

Some of the sensors were calibrated as they were being lowered into the holes. Others were not, as we assumed, incorrectly, that sensors of a given model manufactured by the same company would have essentially the same calibration curve. Results from the uncalibrated sensors are subject to calibration errors of unknown magnitude. In addition, there is some uncertainty as to the depth at which some sensors were emplaced. Thus, there is considerable uncertainty in the absolute water pressures, but the direction 
b
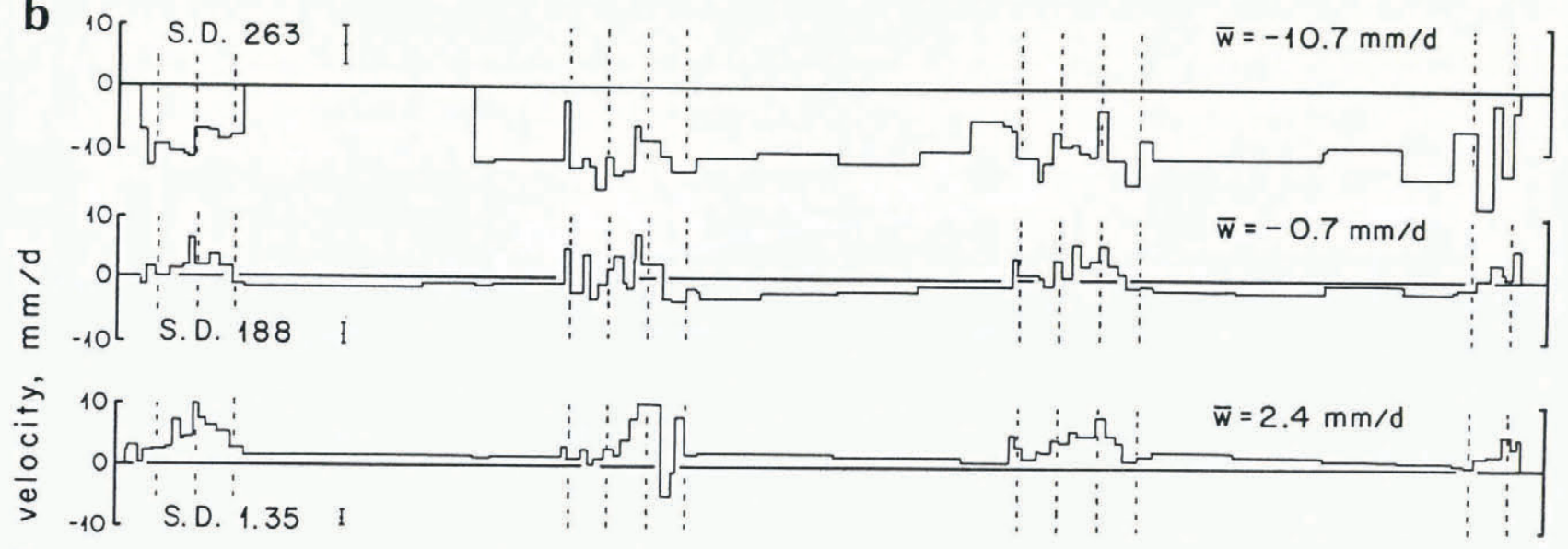

ত
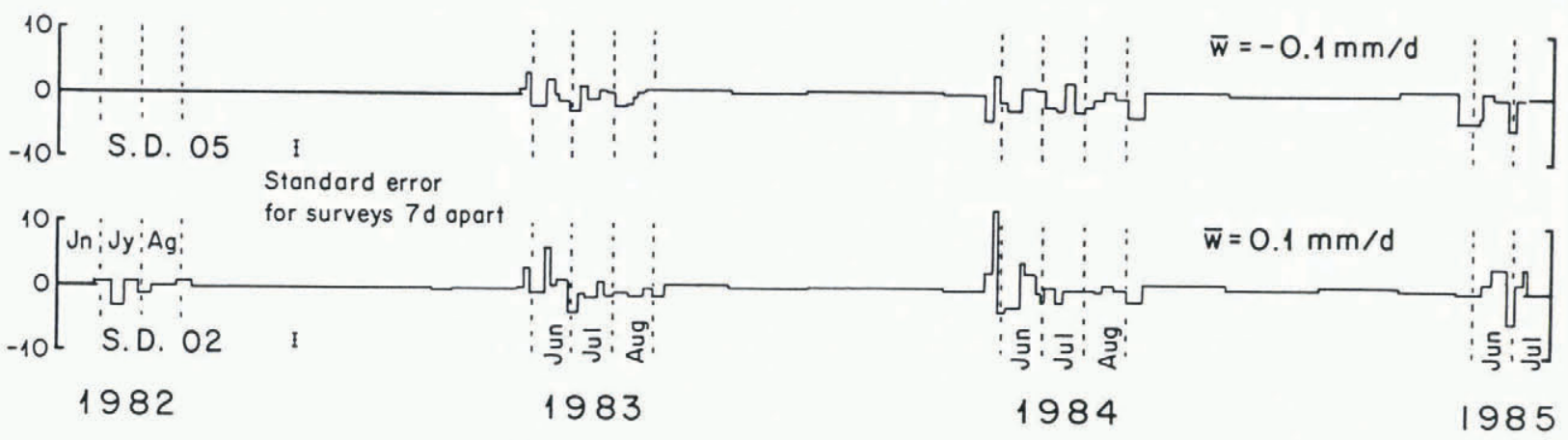

of pressure changes and their approximate magnitude are believed to be reliable.

In holes drilled up-glacier from stake 1.35, water levels usually drop during drilling but rarely oscillate appreciably thereafter. We originally thought that these holes had not made contact with the glacial drainage system, and hence of ten did not instrument them. We now believe that subglacial water pressures are consistently high in this part of the glacier, averaging $\sim 90 \%$ of overburden pressure, and that this is somehow related to the existence of the till layer (Hooke and others, 1988).

\section{RESULTS}

\section{Velocities}

The mean velocities of the stakes are plotted in Figure 1 , using vectors to show the magnitude and direction of the horizontal velocities and numbers at the ends of the vectors to give the vertical velocities. In addition, the longitudinal variation in mean annual velocity and of the mean velocity during July 1983, are plotted in Figure 2. Finally, the mean of the velocities of the several stakes in each strain diamond between each pair of surveys are shown as "staircase" diagrams in Figure 3. The major velocity variations shown in Figure 3 were present in the individual staircase diagrams for all stakes in the respective diamonds, and also in staircase diagrams for stakes displaced up-glacier, down-glacier, and laterally from the diamonds. There was some spatial variation in the amplitude of the peaks, but not enough to obscure the dominant patterns.

Superimposed on the diagram for strain diamond 02 in Figure $3 \mathrm{a}$ is a plot of the $5 \mathrm{~d}$ running mean of the daily temperatures at the field station. Beneath this are plots of daily precipitation and of water-pressure variations in the five bore holes and two moulins shown in Figure 1a. In the latter we plot $5 \mathrm{~d}$ running means of the peak pressure during any given day. As just mentioned, the variations during the summer were actually strongly diurnal in all holes below stake 1.35; peak water levels in the late afternoon were of ten as much as $70 \mathrm{~m}$ above the minimum levels in the early morning (Fig. 4).

The spatial variations in mean velocity (Fig. 1) are consistent with expectation. The horizontal velocity is
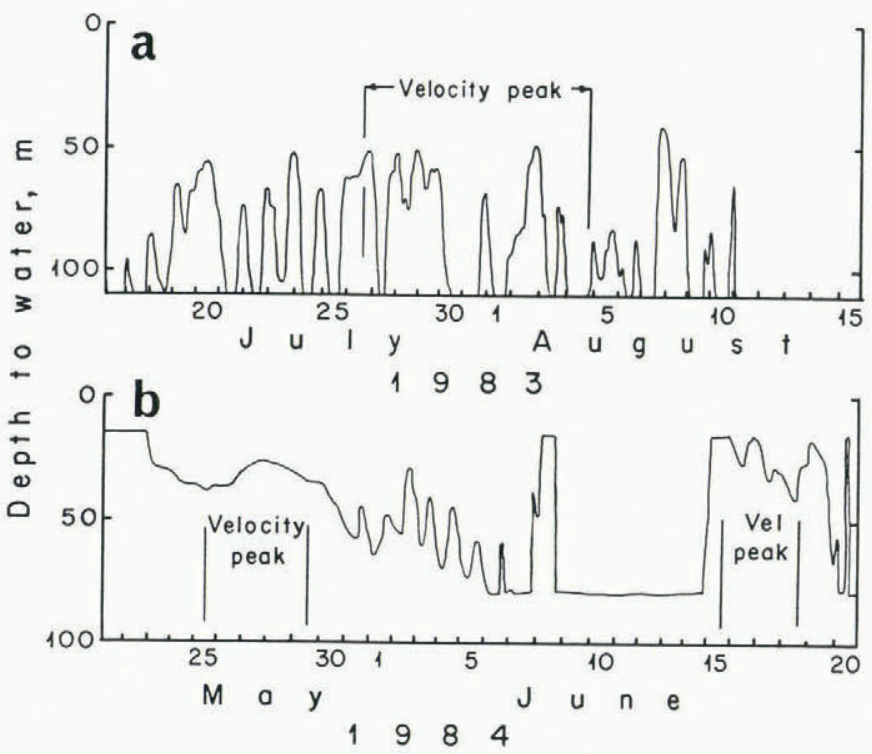

Fig. 4. a. Detailed record of water-level variations in bore hole 83-2 prior to and during velocity peak of late July 1983. b. Detailed record of water-level variations in bore hole 83-8 prior to and during velocity peaks of late May and mid-June 1984.

highest on the steeper slopes in the firn area. In the ablation area, it decreases outward from the center line towards the margin. The most negative vertical velocities are also in the firn area where extending strain-rates (Fig. 5a) and steep slopes combine to give a strong downward component to the flow. Low but positive vertical velocities are the rule in the region of compressive flow in the ablation area, though negative vertical velocities occur locally in areas of steeper slope and in an area of extending flow over the riegel beneath stake 07 .

\section{Horizontal velocities}

There are a number of interesting features in the pattern of horizontal velocities shown in Figures 2 and $3 a$. 


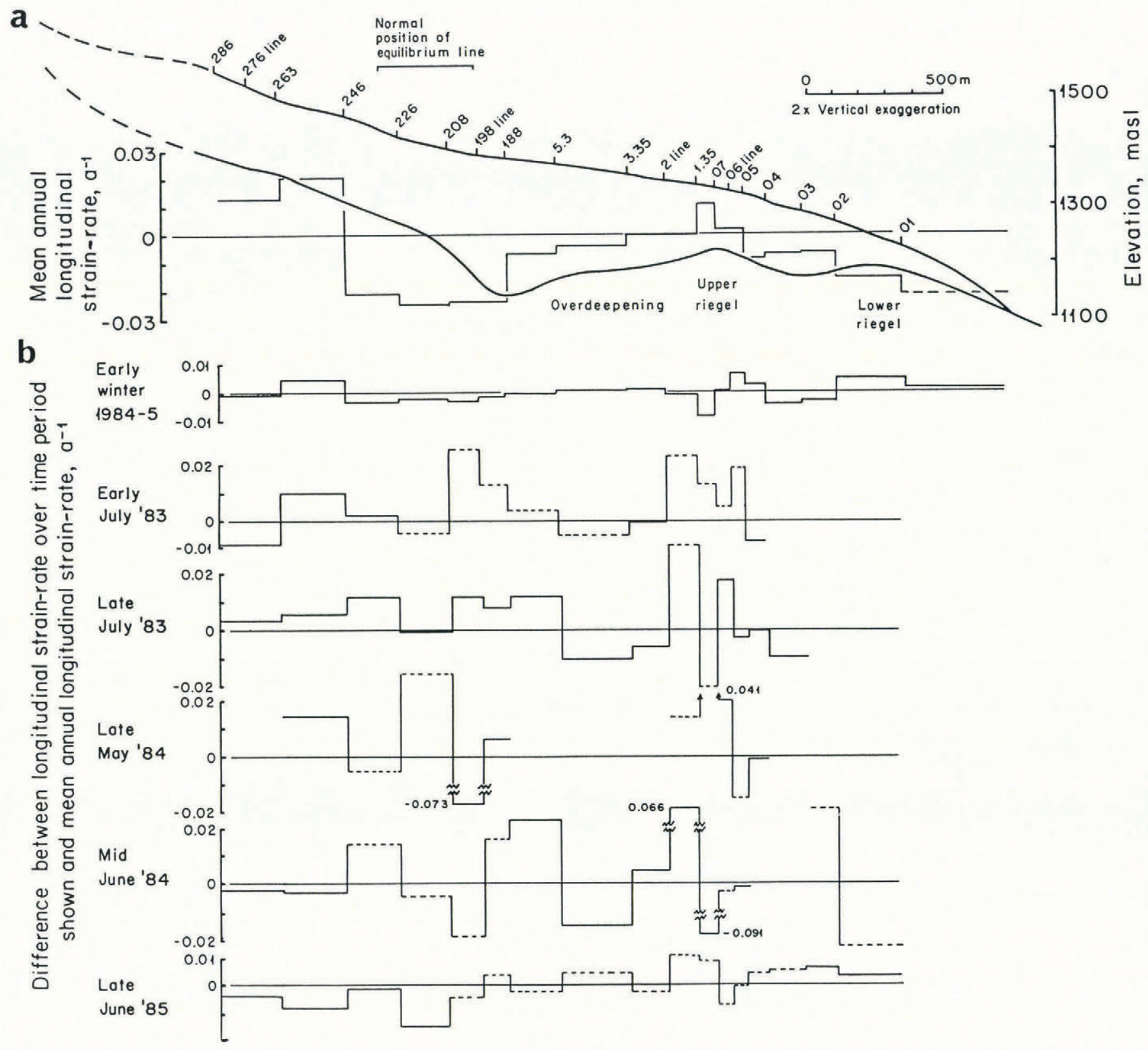

Fig. 5a. Mean annual longitudinal strain-rate superimposed on longitudinal cross-section of the glacier. $b$. Differences between longitudinal strain-rates over six selected time periods and mean annual longitudinal strain-rate. Positive values indicate that $\dot{\varepsilon}_{x x}$ over the relevant time period is higher (more extending or less compressive) than the mean annual value. Gaps occur where data are missing for certain surveys. Dashed sections of these curves are less reliable than solid sections, either because a stake was cut just before or just after the event, or because the azimuth of the flow deviated significantly from the norm during the event, suggesting a possible survey error.

First, there is a marked increase in seasonality with distance down-glacier. This is attributed, in part, to the contrast between the uniformly high and relatively constant water pressures in the overdeepening and the large diurnal pressure variations further down-glacier. The down-glacier decrease in ice thickness, particularly in the lower four strain diamonds, may be a contributing factor. With smaller ice thicknesses, a given increase in water pressure will be a larger fraction of the overburden pressure, and will therefore have a larger influence on the velocity (e.g. Bindschadler, 1983; Iken and Bindschadler, 1986).

Secondly, comparison of the temperature and precipitation records with the velocity variations reveals that each of the latter corresponds to a period of rising temperatures (resulting in increasing ablation rates) or with rainstorms of appreciable size or duration. Where data on water pressure are available, high water pressures generally accompanied the velocity peak. Several specific examples will be cited to illustrate these points:
1. In late June and early July 1982, a sharp increase in velocity in all strain diamonds then in use is correlated with an increase in temperature. Water levels in bore hole 82-1 increased slightly and water levels were generally high in moulin M2. Slightly after mid-July, a comparable increase in temperature, accompanied by rain, caused an increase in water pressure in moulin M2, but this had a noticeable effect on velocity only in diamond 1.35. Another increase in temperature and water pressure in late July had no effect at all.

2. In mid-June 1983, a low velocity peak in strain diamonds 03 and 05 is correlated with a temperature peak and high water levels in moulin Ml.

3. In late June 1983, the first major peak in velocity is correlated with a period of increasing temperature and rainy weather. (The subsequent temperature peak had no noticeable effect.) No water-pressure measurements are available for this time period.

4. The velocity peak in late July 1983 is again correlated 
with a temperature peak and accompanying rain. The peak in the $5 \mathrm{~d}$ running mean of the daily maximum water pressures actually precedes the velocity peak. However, in the more detailed record of the pressure variations (Fig. 4a), it will be seen that high water levels prevailed during the first part of the time interval spanned by the velocity peak.

5. Two subsequent smaller temperature rises in August and September 1983, the second accompanied by a good deal of rain, had appreciable effects on water pressure, but only in diamond 1.35 was there a corresponding peak in velocity.

6. Water pressures in bore holes 83-6 and 83-8 generally increased during the winter of 1983-84, but velocities decreased.

7. The first velocity peak in 1984 occurred in response to rising temperatures in late May. The increased water input resulted in rising water levels in bore holes prior to the velocity peak. By the time of the peak, however, water levels had dropped and were oscillating (Fig. 4b). The temperature peak occurred still later.

8. The second velocity peak in 1984 also occurred in response to sharply rising temperatures, which again resulted in high water levels in bore holes (Fig. 4b). (The more gradual rise in temperature and the accompanying rainfalls that followed during the next $50 \mathrm{~d}$ or so resulted in high water levels in bore holes, but this had practically no effect on velocity.)

9. The sharp rise in water pressure in September 1984 occurred in response to rain during the $7 \mathrm{~d}$ immediately preceding the last survey of the summer, and is visible in records from two moulins and three bore holes. Although this event occurred after a period of over 2 weeks with low water pressures, it did not result in a velocity peak. However, a distinct strain event did occur during this time, with compression between stakes 3.35 and 1.35 , where the average strain-rate is 0 , and with more than normal extension between stakes 07 and 05 .

Noteworthy is the fact that not all periods of high temperature, rainfall, or water pressure resulted in increases in velocity. In the case of temperature and rainfall, it seems that preceding periods of high water input to the glacier probably opened the channel system sufficiently that renewed high inputs could pass through it without raising the water pressure. It is less obvious why some periods of high water pressure did not result in increases in velocity. Among possible explanations are: (1) use of $5 \mathrm{~d}$ running means of peak pressures obscures important relations; (2) water pressures measured in bore holes located down-glacier from the riegel are not representative of those controlling the velocity; (3) velocities respond more to pressure changes than to absolute pressures.

The azimuths of the flow vectors also appear to vary systematically under some circumstances. In an experiment in 1987 on the south side of the glacier, near bore hole 87-1 (Fig. 1), Rydén (1988) noted a systematic counterclockwise rotation of velocity vectors with increase in velocity. The vectors therefore became more nearly parallel to the glacier center line.

We examined the present data to see whether similar changes could be detected. In most cases, azimuths appeared to vary randomly, with deviations from the mean typically being less than $3^{\circ}$. As the standard error in azimuth is estimated to be $\pm 3.3^{\circ}$ for stakes moving $35 \mathrm{~mm} / \mathrm{d}$ surveyed at $7 \mathrm{~d}$ intervals, these variations are assumed to be dominated by random errors in measurement. However, in a few cases there were systematic changes that are consistent either with expectation or with Rydén's observations. For example, during the 3 years of the study, there was a systematic counter-clockwise rotation in the azimuth of flow of stake 208. This is consistent with the overall flow pattern in this part of the glacier. Similarly, the flow vectors of stakes $198_{1}$ and $2 \mathrm{~N}$ rotated systematically inward to become more nearly parallel to the center line during the summer months. There is a suggestion of a similar change in azimuth for stake 2.1 and of an outward rotation of the flow vector of stake 198. However, the records for the latter two stakes are too noisy to be sure that the change is real. During the five major velocity peaks (early July 1983; late July 1983; late May 1984; mid June 1984; and late
June 1985), the azimuths at stakes 208, $03_{2}$, and $03_{3}$ tended to rotate counter-clockwise, and those of stakes $198_{3}, 3.35$, $2.45,1.35,07,06_{2}$, and $06_{3}$, clockwise. The changes at stakes 208 and $198_{3}$ are generally consistent with a longitudinal stretching of the flow and a tendency towards necking during these special events. The changes at the other locations suggest that during such events the surface flow tends to reflect the bed contours more than normally is the case, with flow accelerating into the overdeepening down-glacier from the riegel.

\section{Vertical velocities}

There is also a seasonal variation in vertical velocity in some places on the glacier. In the overdeepening (strain diamonds 188 and 1.35), vertical velocities are systematically $\sim 3 \mathrm{~mm} / \mathrm{d}$ higher during the summer, whereas down-glacier from the riegel (strain diamonds 05 and 02) they are systematically $\sim 1 \mathrm{~mm} / \mathrm{d}$ lower (Fig. $3 \mathrm{~b}$ ).

The vertical velocity at the surface of a glacier, $w_{\mathrm{S}}$, arises from a combination of flow on a sloping bed, vertical strain, and possibly englacial or subglacial cavity formation, thus:

$$
w_{\mathrm{s}}=u_{\mathrm{b}} \tan \beta+\left\langle\dot{\varepsilon}_{z z}\right\rangle Z+\dot{c}
$$

where $u_{\mathrm{b}}$ is the horizontal component of the sliding velocity, $\beta$ is the bed slope, taken as positive when the bed slopes upward in the direction of flow, $\left\langle\dot{\varepsilon}_{z z}\right\rangle$ is the vertical strain-rate averaged over the glacier thickness, $Z$, and $\dot{c}$ is the vertical rate of cavity opening. Of these parameters, $B$ and $Z$ can be obtained from radio echosoundings, and $\left\langle\dot{\varepsilon}_{z z}\right\rangle, u_{\mathrm{b}}$, and $\dot{c}$ must be considered to be unknown for the purposes at hand, although measured surface strain-rates can be used to constrain $\left\langle\dot{\varepsilon}_{z z}\right\rangle$, and there are some bore-hole data that constrain $u_{\mathrm{b}}$ (Hooke and others, 1987; paper in preparation by V. Pohjola and R. LeB. Hooke).

Hooke and others (1983b, 1987) (see also Iken and Bindschadler, 1986, p. 118-19) incorrectly used the horizontal component of the surface velocity, $u_{\mathrm{s}}$, instead of $u_{\mathrm{b}}$ in Equation (1), and incorrectly believed that they could therefore estimate the rate of cavity opening at the bed.

Available data suggest that $\dot{\varepsilon}_{z z}$ varies with depth in valley glaciers (Raymond, 1971; Harrison, 1975). We will now show that, in most cases, the vertical velocities are best understood by appealing to such a depth-dependence of $\dot{\varepsilon}_{z z}$. Assume that $0<u_{\mathrm{b}}<u_{\mathrm{s}}$. Assume further that, if there is any cavity formation, it will occur during the summer. Thus, $\dot{c} \geqslant 0$ during the summer and $\dot{c} \leqslant 0$ during the winter. Finally, assume that $\dot{c}=0$ in the overdeepening. This assumption is supported by the recent results suggesting: (1) that the overdeepening is underlain, at least in part, by a layer of deformable till $\sim 0.5 \mathrm{~m}$ thick (Brand and others, 1987); and (2) that drainage through the overdeepening is englacial rather than subglacial (Hooke and others, 1988). Changes in the degree of dilation of the till layer could result in $\dot{c} \neq 0$. However, an increase in porosity from say 30 to $40 \%$ would probably be more than sufficient to account for the observed variations in velocity (Jones, 1979; Alley and others, 1987). Thus, unless the layer is considerably thicker than we presently believe it is, changes in porosity could not be large enough to effect $w_{\mathrm{S}}$ appreciably,

If $\dot{c}$ and $u_{\mathrm{b}}$ are both $0,\left\langle\dot{\varepsilon}_{z z}\right\rangle Z=w_{\mathrm{S}}$. If $\dot{c}$ is 0 and $u_{\mathrm{b}}=u_{\mathrm{S}},\left\langle\dot{\varepsilon}_{z z}\right\rangle Z=w_{\mathrm{S}}-u_{\mathrm{s}} \tan \beta$. Thus, in the absence of cavity formation, $w_{\mathrm{S}}$ and $w_{\mathrm{S}}-u_{\mathrm{S}} \tan \beta$ represent limiting values of $\left\langle\dot{\varepsilon}_{z z}\right\rangle Z$. Furthermore, if $\dot{\varepsilon}_{z z}$ were independent of depth, $\left\langle\dot{\varepsilon}_{z z}\right\rangle Z$ would equal $\dot{\varepsilon}_{z z \mathrm{~S}} Z$, where $\dot{\varepsilon}_{z z \mathrm{~s}}$ is the value of $\dot{\varepsilon}_{z z}$ at the surface. $\dot{\varepsilon}_{z z \mathrm{~S}}$ is calculated from measured values of $\dot{\varepsilon}_{x x S}$ and $\dot{\varepsilon}_{y y S}$, assuming incompressibility. Thus, when $\dot{\varepsilon}_{z z s^{Z}}$ does not lie between the limiting values for $\left\langle\dot{\varepsilon}_{z Z}\right\rangle Z$, it is likely that $\dot{\varepsilon}_{z z}$ is varying with depth.

Values of $w_{\mathrm{S}}, \dot{\varepsilon}_{z z \mathrm{~S}} Z, w_{\mathrm{S}}-u_{\mathrm{S}} \tan \beta$, and $u_{S}$, averaged over the 3 years of the study (2 years for strain diamond 05), are given in Table I. We have made separate calculations for the summer (July + August) and winter (September-May). June was omitted as it is a transition month, having characteristics of the winter regime in some years and the summer regime in others. The uncertainties shown in Table I are the standard deviations of the values from the 3 (or 2) years of measurement. To the extent that 
TABLE I. INTERPRETATION OF VERTICAL VELOCITIES

$\begin{array}{ccccc}w_{\mathrm{S}} & \dot{\varepsilon}_{z z \mathrm{~s}} Z & w_{\mathrm{s}}-u_{\mathrm{s}} \tan \beta & u_{\mathrm{s}} & \begin{array}{l}\text { Possible variation } \\ \text { in } \dot{\varepsilon}_{z z} \text { with depth }\end{array} \\ \mathrm{mm} / \mathrm{d} & \mathrm{mm} / \mathrm{d} & \mathrm{mm} / \mathrm{d} & \mathrm{mm} / \mathrm{d} & \end{array}$

S.D. 263

$\begin{array}{ll}B=-0.131 & -10.0 \pm 0.7 \\ Z=135 \mathrm{~m} & -10.8 \pm 0.3\end{array}$

S.D. 188

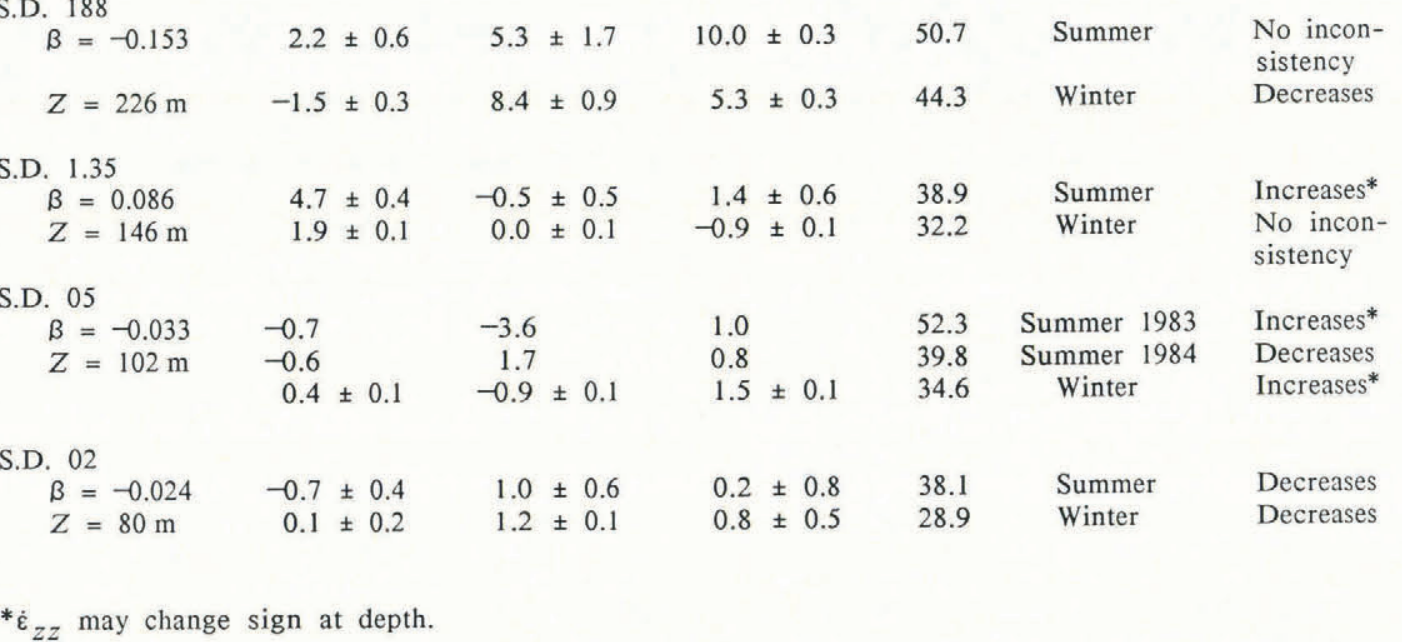

${ }^{*} \dot{\varepsilon}_{z z}$ may change sign at depth.

$5.5 \pm 0.6$

$2.5 \pm 0.5$

$-2.4 \pm 0.5$

$-3.4 \pm 0.3$

58.4

56.7

Summer

Winter

Decreases*

Decreases*

No incon-

Winter $\quad \begin{array}{ll}\text { Sistency } \\ \text { Decreases }\end{array}$

Summer

No incon-

sistency
S.D. 0

there were real inter-annual differences in the flow field, these should overestimate the standard error.

Detailed examination of the data in Table I reveals that $\dot{\varepsilon}_{z z} Z$ lies between its limiting values in only two instances, designated "no inconsistency" in the right-hand column of the table. In six of the remaining cases, the sense of the discrepancy is such that $w_{\mathrm{S}}$ would be higher (less negative or more positive) if $\dot{\varepsilon}_{z z}$ were, in fact, independent of depth. We infer that $\dot{\varepsilon}_{z z}$, which is positive or extending at the surface in these cases, probably decreases with depth. In the remaining three cases the sense of the discrepancy is such that $w_{\mathrm{S}}$ would be lower (more negative or less positive) if $\dot{\varepsilon}_{z z}$ were independent of depth. $\dot{\varepsilon}_{z z}$ is negative at the surface in these cases, so we infer that it becomes less negative at depth.

In five instances, simply reducing $\left|\dot{\varepsilon}_{z z}\right|$ to zero at depth is insufficient to explain the discrepancies. For example, beneath strain diamond 263 the bed slopes downward in the direction of flow and $w_{\mathrm{S}}$ is negative. It appears that only part of this negative $w_{\mathrm{S}}$ can be attributed to the bed slope, so $\left\langle\dot{\varepsilon}_{z z}\right\rangle$ must be negative. However, $\dot{\varepsilon}_{z z S}$ is positive, so it appears that $\dot{\varepsilon}_{z z}$ must change sign at depth.

Two points in Table I merit further comment. First, in strain diamond $05, \dot{\varepsilon}_{z z \mathrm{~S}} Z$ is negative in 1983 and positive in 1984. While this may be due to errors in measurement, it is noteworthy that 1983 was a year of rather high summer velocities. Secondly, over the riegel somewhat up-glacier from strain diamond 1.35 , bore-hole deformation measurements have suggested that the velocity at the bed may exceed that at the surface by a factor of four to five in late July and early August (Hooke and others, 1987). Thus, in this case, $w_{S}-u_{S} \tan \beta$ may not be a limiting value of $\left\langle\dot{\varepsilon}_{z z}\right\rangle Z$. However, bore-hole deformation measurements in 1985 in the middle of strain diamond 1.35 suggest that the extrusion flow does not extend this far up-glacier.

Given the initial assumptions, there is only one instance in which the above results could be explained by a non-zero value of $\dot{c}$. This is during the summer of 1983 in strain diamond 05 , where the data could be interpreted as indicating that $\dot{c}$ was positive.

We return now to the problem of seasonal variations in $w_{\mathrm{S}}$ noted in the first paragraph of this section. The decrease in $w_{\mathrm{S}}$ down-glacier from the riegel during the summer suggests that here the longitudinal strain-rate, $\dot{\varepsilon}_{x x}$, becomes less compressive or the transverse strain-rate, $\dot{\varepsilon}_{y y}$, more extending at this time of year. The seasonal increase in velocity of strain diamond 05 tends to be greater than that of diamond 02 , so $\dot{\varepsilon}_{x x \mathrm{~s}}$ becomes more compressive. On the other hand, velocity vectors near the margins (stakes $03_{1}$ and 03 ) tend to rotate outward, so $\dot{\varepsilon}_{y y s}$ becomes more extending. The change in $\dot{\varepsilon}_{x x s}$ is larger. Possibly $\dot{\varepsilon}_{x x}$ increases (becomes less compressive) with depth, and does so more rapidly during the summer than during the winter. However, bore-hole deformation measurements (Raymond, 1971; paper in preparation by V. Pohjola and R.LeB. Hooke) suggest that $\dot{\varepsilon}_{y y}$ becomes more extending with depth in the ablation area of a valley glacier. If this effect increases seasonally here, it could explain the decrease in $w_{\mathrm{S}}$ near the center line. Noteworthy in this regard is the fact that $w_{\mathrm{S}}$ increases during the summer at stake $03_{4}$.

The seasonal increase in $w_{\mathrm{S}}$ throughout the overdeepening, on the other hand, suggests an increase in longitudinal compression or a decrease in transverse extension. The summer increase in $u_{\mathrm{s}}$ is slightly larger in strain diamond 1.35 than in diamond 188 , so $\dot{\varepsilon}_{x x \mathrm{~s}}$ tends to become less compressive (Table I). However, the values for strain diamond 188 in Table I imply that during the summer, $\dot{\varepsilon}_{z z}$ may not decrease with depth, whereas during the winter it very probably does. This suggests the possibility of an increase in horizontal compression at depth during the summer. Additional analyses presented below suggest that this is due to a decrease in basal drag near the middle of the overdeepening at this time of year. In addition, surface-velocity data and bore-hole deformation measurements indicate that here, in contrast to the situation further down-glacier, $\dot{\varepsilon}_{y y}$ becomes less positive during the summer both at the surface and at depth. Consistent with such a change in $\dot{\varepsilon}_{y y}$ is the fact that vertical velocities along the sides of the glacier (stakes $198_{1}, 198_{4}, 2.1$, and $2 \mathrm{~N}$ ) increase an average of only $\sim 2 \mathrm{~mm} / \mathrm{d}$ during the summer, rather than $\sim 3 \mathrm{~mm} / \mathrm{d}$ as in the central part.

In the case of the overdeepening, we can make a rough calculation of the magnitude of these changes. Over a control area $400 \mathrm{~m}$ wide in the center of the glacier and extending $700 \mathrm{~m}$ from stake 188 to stake 1.35, an increase in vertical velocity of $3 \mathrm{~mm} / \mathrm{d}$ would require an extra influx of ice of $\sim 850 \mathrm{~m}^{3} / \mathrm{d}$. A summer decrease in basal drag beneath stake 188 would straighten the velocity profile and thus increase the flux; assuming laminar flow (Nye, 1952, equation (2)) and holding the surface velocity constant, a decrease from 0.8 to $0.6 \mathrm{bar}(0.08$ to $0.06 \mathrm{MPa})$ would increase the flux here by $\sim 400 \mathrm{~m}^{3} / \mathrm{d}$. At the down-glacier end of the control area, the ice is only about half as thick, so a comparable change in basal drag would increase the loss of ice from the control area by only $\sim 100 \mathrm{~m}^{3} / \mathrm{d}$. Along the sides of the control area, the surface-velocity data suggest an inward rotation of velocity vectors of $\sim 1.3^{\circ}$ 
during the summer (ignoring a rotation in the opposite direction at stake $198_{4}$, which is in a somewhat special position at the base of a steep slope leading down from the accumulation area). $u_{\mathrm{s}}$ is $\sim 30 \mathrm{~mm} / \mathrm{d}$ here, so such a change would correspond to a decrease in outward flux of $\sim 170 \mathrm{~m}^{3} / \mathrm{d}$. Bore-hole deformation measurements suggest that $\dot{\varepsilon}_{\text {yy }}$ may decrease even more at depth. For example, relative to vectors at the surface, the outward rotation of velocity vectors in the lowermost $50 \mathrm{~m}$ of hole $87-1$ (Fig. 1) was $2-3^{\circ}$ less during the last two-thirds of July 1987. Such a change, if it occurred on both sides of the control area, would decrease the outward flux of ice by an additional $\sim 150 \mathrm{~m}^{3} / \mathrm{d}$. Thus, with due consideration for the uncertainties in the calculations, it appears that seasonal changes in the variation of longitudinal and transverse strain-rate with depth probably can account for the increased vertical velocity in the overdeepening.

\section{Longitudinal strain-rates along glacier center line}

Mean annual longitudinal strain-rates were calculated between stakes lying along or near the center line of the glacier. (Stakes $06_{2}$ and $06_{3}$ were considered to be near the center line for this purpose; their average velocity was used in the calculations.) These strain-rates are shown in Figure $5 \mathrm{a}$, superimposed on a cross-section of the glacier.

As expected, strain-rates are generally extending in the accumulation area and compressive in the ablation area. The most notable exception to this is over the riegel beneath stake 07 , where the increase in slope of the glacier surface leads to extending strain-rates that are high enough to result in crevassing. The rather high compression beneath the equilibrium line is also contrary to normal expectations. This results from the combination of the down-glacier decrease in surface slope in this area and the downward thickening of the glacier as it enters the overdeepening.

Longitudinal strain-rates were also calculated over shorter time periods, and the difference between the mean annual longitudinal strain-rate and that during these time periods has been plotted in Figure $5 \mathrm{~b}$. To provide greater resolution in strain diamonds 1.35 and 188 , the velocity at the centers of these diamonds was estimated by averaging the velocities at the two stakes on either side of the center; thus strain-rates were also calculated between, for example, stake 208 and the 198 line and between the 198 line and stake 188 (Fig. lb). The absolute values of these strain-rates are biased because velocities decrease towards the margins, but differences between these values and the corresponding mean annual values are probably meaningful.

In the early winter (late November 1984 to late January 1985), strain-rates between stakes 246 and 188 are more compressive than average (Fig. 5b). Apparently, the winter deceleration is faster in the overdeepening than on the steeper slope up-glacier therefrom. There is also, over both riegels, a pattern of relative (with respect to the mean annual) compression above the riegel (stakes $1.35 \rightarrow 07$ and $04 \rightarrow 02$ ), and a compensating extension below the riegel, as if the glacier had grounded on the riegel.

Changes in longitudinal strain-rate during the highvelocity events are discussed in the next section.

Response of glacier to short periods of high water input

To study the dynamic response of the glacier to high water inputs resulting from warm weather or rain, the five major high-velocity events between June 1983 and June 1985 (Fig. 3a) were investigated in greater detail. First, we studied the difference between the strain-rate during the event and the mean annual longitudinal strain-rate (Fig. 5b), and secondly, we used a force-balance calculation (Van der Veen and Whillans, 1989) to investigate changes in basal drag during the events.

In interpreting these calculations, two points should be borne in mind. First, because, by definition, some velocity measurements will be in error by an amount considerably in excess of the estimate of standard error given earlier, we do not rely upon any single measurement; instead, we seek patterns of behavior that are consistent among many or all of the five events. Secondly, the actual duration of a velocity peak may have been much shorter than the time interval between surveys, or may have spanned parts of two survey periods. Thus, it is unlikely that the timing of the surveys would be such as to catch any two events at precisely the same stage.
Two consistent patterns in the changes in longitudinal strain-rate during the events (Fig. 5b) merit comment. First, between stakes 208 and 5.3 there is always a region over which strain-rates are less compressive than the mean annual rate. In general, strain-rates remain compressive during the velocity peaks but between stakes 188 and 5.3 they do, in fact, become extending in two cases. In contrast, downglacier from stake 5.3, in some cases extending down to the 2 line, strain-rates during the velocity peaks are generally more compressive than normal. Down-glacier from the upper riegel (stake 07) there is, in most cases, a similar pattern of abnormal extension (or less than normal compression) followed down-glacier by a zone of abnormal compression.

High water inputs are likely to result in a reduction in basal drag, thus increasing the sliding speed; the observations just discussed suggest that in the central part of the glacier the most effective reduction occurs along the adverse slope leading out of the overdeepening, and in particular in the vicinity of stake 5.3. The zone of enhanced compression down-glacier from this interval rules out the possibility of explaining the velocity increase by tensional pulling from accelerating down-glacier ice. Likewise, the change from compression to extension between stakes 188 and 5.3 in two cases rules out the possibility of explaining it by push from up-glacier.

Secondly, in the area just up-glacier from the upper riegel, there was abnormal extension in all five of the events under consideration. In three of these, the extension continued down-glacier to or below stake 07 , but in the other two the strain is compressive between stakes 1.35 and 07. This latter suggests that the acceleration in the vicinity of stake 1.35 is not due to pull from the more obvious accelerations that occur below the riegel. Rather, we hypothesize that subglacial water pressures may increase more here, relative to the area between stake 5.3 and the 2 line, because the bottom topography (Fig. 1) forces water toward the glacier center line as it passes over the riegel. Immediately after these events the strain-rate between stake 1.35 and the 2 line becomes either appreciably less extending or, in three of the five cases, strongly compressive. This suggests that the effects of a high water input last longer in the overdeepening.

The force-balance analysis further elucidates the first of these points. In this analysis, a block of the glacier is selected (e.g. Fig. 6), and measured strain-rates are used to estimate the longitudinal forces on its up-glacier and down-glacier ends and shear forces on its sides. Subtracting the body force leaves the drag on the bed as a residual. Summing forces in the $x$ or down-glacier direction yields:

$$
\begin{aligned}
F_{x}= & R_{x x}(n \Delta y \Delta z)_{\mathrm{u}}-R_{x x}(n \Delta y \Delta z)_{\mathrm{d}}+R_{y x}(n \Delta x \Delta z)_{\mathrm{S}}- \\
& -R_{y x}(n \Delta x \Delta z)_{\mathrm{n}}-\rho g \Delta x \Delta y \Delta z S-\tau_{\mathrm{b}} \Delta x \Delta y=0
\end{aligned}
$$

where $R$ s are resistive stresses (using Van der Veen and Whillans' (1989) terminology), $\Delta x, \Delta y$, and $\Delta z$ are the average dimensions of the block, $\boldsymbol{n}$ is the outwardly directed unit vector normal to the face, $\rho$ is the density of ice, $g$ is the acceleration due to gravity, $S$ is the surface slope (which is negative in the $+x$-direction), and $\tau_{\mathrm{b}}$ is the desired drag stress. The subscripts $x$ and $y$ refer to the horizontal coordinate directions; following normal convention, the first subscript in a pair gives the normal to the plane on which the stress acts, and the second gives the direction of the stress (Jaeger, 1969, p. 3). The subscripts u, d, n, and $s$ refer to the up-glacier, down-glacier, north, and south sides of the block.

Dividing by $\Delta x \Delta y$ and letting $\Delta z=Z$ yields:

$$
\text { A } \quad \text { B }
$$

$$
\left(R_{x x \mathrm{u}^{n}} n Z_{\mathrm{u}}-R_{x x \mathrm{~d}} n Z_{\mathrm{d}}\right) / \Delta x+\left(R_{y x \mathrm{~s}} n Z_{\mathrm{s}}-R_{y x \mathrm{n}} n Z_{\mathrm{n}}\right) \Delta y-
$$

\section{C}

$$
-\rho g Z S=\tau_{\mathrm{b}} .
$$

The resistive stresses are defined by $R_{i j}=\tau_{i j}-\delta_{i j} L(i$, $j,=x, y, z$ ) where $L=-\rho g Z, \quad \tau_{i j}$ is the total (not 

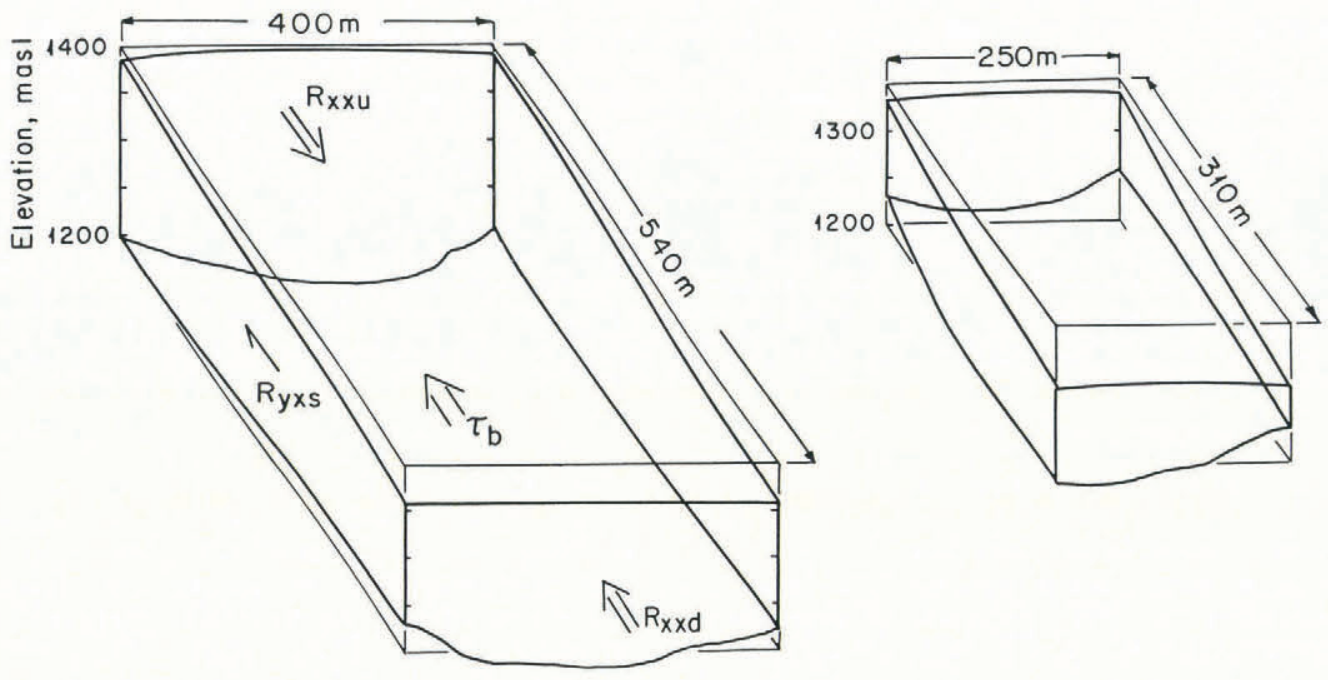

Fig. 6. Three-dimensional sketches of blocks used in force-balance calculation. Locations of blocks are shown in Figure 1.

deviatoric) stress, and $\delta_{i j}$ is the Kronecker delta. We assume that $\tau_{z z}=L$, which means that there are no "bridging effects" resulting, for example, from extensive separation of ice from the bed. Thus $R_{z z}=0$. Then, using a Glen-type flow law, $\dot{\varepsilon}_{\mathrm{e}}=\left(\tau_{\mathrm{e}} / B\right)^{n}$, we find, after some manipulation, that:

$$
\begin{aligned}
& R_{x x}=B \dot{\varepsilon}_{\mathrm{e}}^{(1-n) / n}\left(2 \dot{\varepsilon}_{x x}+\dot{\varepsilon}_{y y}\right) \\
& R_{y x}=B \dot{\varepsilon}_{\mathrm{e}}^{(1-n) / n} \dot{\varepsilon}_{y x}
\end{aligned}
$$

(Van der Veen and Whillans, 1989) where $\tau_{\mathrm{e}}$ and $\dot{\varepsilon}_{\mathrm{e}}$ are the effective stress deviator and strain-rate, respectively. Given the strain-rates required to evaluate Equations (4) and the dimensions of the block, Equation (3) can be solved for $\tau_{\mathrm{b}}$.

In the present application, strain-rates were determined from their definitions in terms of velocity derivatives. The latter were estimated from first differences after first determining the components of the velocities of the relevant stakes parallel to the sides of the block. Appendix II gives details of the specific stakes used to obtain the required velocity derivatives.

Calculations of the absolute value of the drag in this way make the critical assumptions that strain-rates are: (1) independent of depth, and (2) sufficiently uniform over the ends and sides of the block that the values determined above can be applied over these respective surfaces. However, here we are concerned primarily with changes in drag between different time periods. Thus, for our purposes, we assume only that any such lateral or vertical variations in strain-rate were sufficiently similar between the different time periods studied to make comparisons meaningful.

The essential result of these calculations is that, during the high-velocity periods, the basal drag in the overdeepening seems to have been reduced anywhere from 16 to $40 \%$ relative to its winter (31 October 1983-3 March 1984) value. In contrast, below the riegel the basal drag seems to have increased significantly during two of three events, and to have been reduced only slightly during the third. (Unfortunately, because data for some stakes are missing or believed to be unreliable, calculations could not be done for this area during the other two time periods.)

The changes in drag appear to result principally from changes in the longitudinal stresses. This can be seen in columns 8 and 10 of Table II, where the values of terms A and $B$ in Equation (3) are given. Compared with the winter values, the values of term A (longitudinal forces on ends) vary by up to $0.25 \mathrm{bar}(25 \mathrm{kPa})$, while those of term B (shear forces on sides) vary less than $0.1 \mathrm{bar}(10 \mathrm{kPa})$. However, the longitudinal stress is not necessarily the independent variable.
In the case of the block in the overdeepening, the independent variable is probably $\tau_{\mathrm{b}}$; decreases in drag, presumably caused by increases in water pressure, result in an acceleration. At the up-glacier end of the block, as already noted (Fig. 5b), this results in a decrease in compression and in some cases even extension. At the down-glacier end, in most cases, there is a corresponding increase in compression. Shear stresses along the sides increase modestly in all cases.

As might be expected from the above discussion, there is a reasonably good correlation between the percentage change in drag in the overdeepening and the change in $\dot{\varepsilon}_{x x s}$ at the up-glacier end of the block (Fig. 7). Correlations were also sought between the velocities of stakes and the percentage reduction in drag. However, longitudinal strain-rates within the block apparently vary sufficiently among the various events (Fig. 5b) to render such correlations weak.

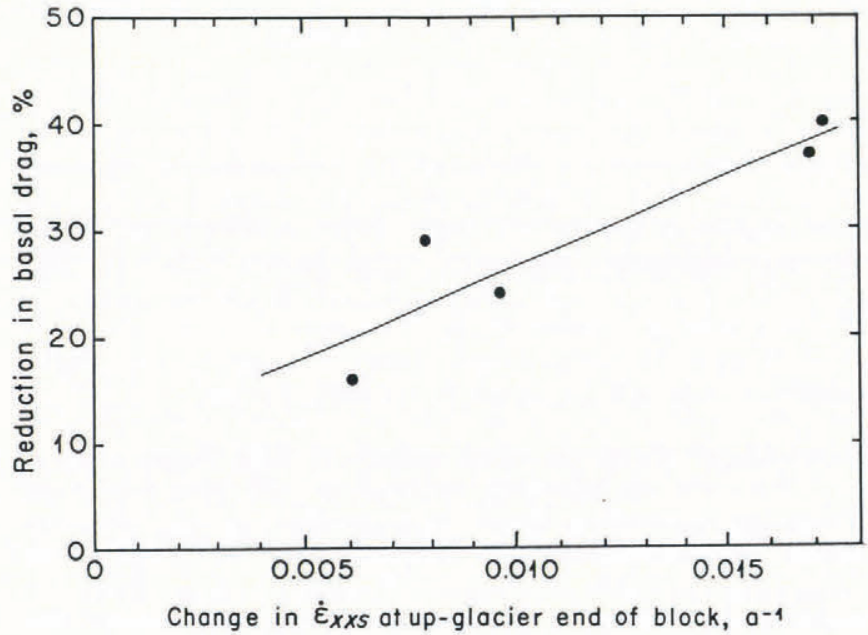

Fig. 7. Relation between percentage change in basal drag in the overdeepening and $\dot{\varepsilon}_{x x s}$ near stake 188 .

On the smaller down-glacier block the situation is quite different. In two of the three cases, the normal extension at the up-glacier end of the block changes to compression, indicating push from up-glacier, and in these two cases the normal compression at the down-glacier end of the block is reduced, in one case even becoming extension. The clear implication is that changes in basal water pressure have affected areas over the riegels up-glacier and down-glacier from this block more than the area directly beneath the block. In response to the resulting push from up-glacier and decreased resistance down-glacier, the block has accelerated, 
TABLE II. FORCE-BALANCE CALCULATIONS
(1)
(2) (3)
(4)
(5)
(6)
(7)
(8) (9)
(10)
(11)
(12)

Up-glacier end Down-glacier end

Sides

\begin{tabular}{|c|c|c|c|c|c|c|c|c|c|c|c|c|}
\hline Up-glacier block & $\begin{array}{l}\dot{\varepsilon}_{x x} \\
\mathrm{a}^{-1}\end{array}$ & $\begin{array}{l}\dot{\varepsilon}_{y y} \\
\mathrm{a}^{-1}\end{array}$ & $\begin{array}{l}\dot{\varepsilon}_{x y} \\
\mathrm{a}^{-1}\end{array}$ & $\begin{array}{l}\dot{\varepsilon}_{x x} \\
\mathrm{a}^{-1}\end{array}$ & $\begin{array}{l}\dot{\varepsilon}_{y y} \\
\mathrm{a}^{-1}\end{array}$ & $\begin{array}{l}\dot{\varepsilon}_{x y} \\
\mathrm{a}^{-1}\end{array}$ & $\begin{array}{c}\text { Term A, } \\
\text { Equation } \\
\text { (3) } \\
\text { bar }\end{array}$ & $\begin{array}{c}\left|\dot{\varepsilon}_{y x}\right| \\
\mathrm{a}^{-1}\end{array}$ & $\begin{array}{l}\text { Term B, } \\
\text { Equation } \\
\text { (3) } \\
\text { bar }\end{array}$ & $\begin{array}{l}\text { Body } \\
\text { stress } \\
\text { bar }\end{array}$ & $\begin{array}{l}{ }^{T_{b}} \\
\text { bar }\end{array}$ & $\begin{array}{l}\% \text { change in } \\
\tau_{\mathrm{b}} \text { relative } \\
\text { to winter }\end{array}$ \\
\hline Winter & -0.0160 & 0.0172 & -0.0013 & -0.0041 & 0.0006 & 0.0002 & +0.01 & 0.0139 & -0.34 & 1.15 & -0.82 & - \\
\hline Early & & & & & & & & & & & & \\
\hline $\begin{array}{l}\text { July } 1983 \\
\text { Late }\end{array}$ & 0.0008 & 0.0152 & 0.0013 & -0.0050 & 0.0049 & -0.0056 & -0.25 & 0.0170 & -0.38 & 1.15 & -0.52 & -37 \\
\hline $\begin{array}{l}\text { July } 1983 \\
\text { Late }\end{array}$ & -0.0063 & 0.0219 & -0.0061 & -0.0106 & 0.0116 & 0.0075 & -0.17 & 0.0187 & -0.36 & 1.15 & -0.62 & -24 \\
\hline $\begin{array}{l}\text { May } 1984 \\
\text { Mid June }\end{array}$ & -0.0081 & 0.0113 & 0.0140 & -0.0183 & 0.0037 & -0.0046 & -0.19 & 0.0185 & -0.38 & 1.15 & -0.58 & -29 \\
\hline $\begin{array}{l}1984 \\
\text { Late }\end{array}$ & 0.0012 & 0.0042 & -0.0003 & -0.0015 & -0.0053 & 0.0048 & -0.26 & 0.0160 & -0.40 & 1.15 & -0.49 & -40 \\
\hline June 1985 & -0.0098 & 0.0120 & -0.0003 & -0.0067 & -0.0034 & -0.0042 & -0.07 & 0.0166 & -0.38 & 1.15 & -0.69 & -16 \\
\hline Down-glacier block & & & & & & & & & & & & \\
\hline Winter & 0.0059 & -0.0004 & -0.0065 & -0.0082 & 0.0034 & 0.0070 & -0.28 & -0.0142 & -0.25 & 1.45 & -0.92 & \\
\hline May 1984 & 0.0004 & -0.0128 & 0.0148 & -0.0528 & -0.0236 & -0.0281 & -0.23 & $\begin{array}{r}0.0336 \\
-0.0581\end{array}$ & -0.31 & 1.45 & -0.91 & -1 \\
\hline $\begin{array}{l}\text { Mid-June } \\
1984\end{array}$ & -0.0015 & -0.0048 & -0.0064 & 0.0369 & -0.0007 & -0.0020 & +0.40 & $\begin{array}{r}0.0074 \\
-0.0153\end{array}$ & -0.15 & 1.45 & -1.70 & +84 \\
\hline $\begin{array}{l}\text { Late } \\
\text { June } 1985\end{array}$ & -0.0015 & -0.0077 & -0.0077 & -0.0018 & 0.0021 & 0.0015 & +0.09 & $\begin{array}{r}0.0091 \\
-0.0298\end{array}$ & -0.25 & 1.45 & -1.29 & +40 \\
\hline
\end{tabular}

* Upper number is south side and lower number is north side.

increasing shear strain-rates on the sides and base. Due to the proportionality between stress and strain-rate, the latter has resulted in an increase in drag at the base.

During the late May 1984 event, the situation in the vicinity of the down-glacier block was slightly different. In this case, it appears that drag was decreased beneath the block and this, in conjunction with a little less resistive "pull" from up-glacier, resulted in an acceleration of the block, which then rammed into the still lower part of the tongue, producing a large compression (Table II, col. 5). It is perhaps significant that during this event, which occurred earlier in the melt season than any of the others, compressive strain-rates at the down-glacier ends of both blocks increased markedly. Relevant is the fact that the two major areas of water input to the glacier are areas of crevassing just up-glacier from the two blocks. The change-over from winter to summer drainage conditions may progress down-glacier from these areas of water input.

The extent to which variations in strain-rate with depth might affect these calculations should be addressed. From the preceding discussion, it would appear that $\dot{\varepsilon}_{x x}$ at the up-glacier ends of the blocks is most critical. Were we to assume that $\dot{\varepsilon}_{x x}$ decreased linearly with depth here, and thus, for example, use one-half of its surface value in the calculations for the larger block, the winter value of $\tau_{b}$ would decrease from -0.82 to $-0.63 \mathrm{bar}$, and the May 1984 value, as an example, would be reduced from -0.58 to -0.49 bar. The reduction in basal drag would then be $22 \%$ instead of $29 \%$. $\dot{\varepsilon}_{x x}$ probably decreases with depth, and the decrease is probably less in the summer than during the winter, judging from the discussion of vertical velocities above. Thus, the reduction in drag is probably overestimated in Table II. However, the decrease in the depth dependence of $\dot{\varepsilon}_{z z}$ during the summer strongly suggests a decrease in drag at that time of year. Thus, the errors in the estimates of $\tau_{\mathrm{b}}$ in Table II are unlikely to be so high as to negate the qualitative conclusions reached.

\section{CONCLUSIONS}

The horizontal speed of Storglaciären increases abruptly in the late spring or early summer, after having declined gradually during the winter. Additional velocity peaks occurred later in the summer during the present study (Fig. 3a), in contrast to the situation in 1981 and 1982 (Hooke and others, 1983b). Similar patterns of velocity variation have been observed previously on other glaciers. In 1969 , the speed of Nisqually Glacier peaked in early June near the equilibrium line and in late June near the terminus (Hodge, 1974). A noteworthy difference, however, is the fact that Nisqually Glacier accelerates during the winter and spring, whereas Storglaciären decelerates. The reasons for this difference are not clear, particularly in view of the increase in water pressure beneath at least part of Storglaciären (Fig. 3a) during the winter. Winter accelerations have also been observed on Variegated Glacier during the initial phases of its 1982-83 surge (Kamb and others, 1985). Mid-season velocity peaks have been observed on Unteraargletscher (Iken and others, 1983) and Findelengletscher (Iken and Bindschadler, 1986). In the case of Findelengletscher, simultaneous water-pressure measurements demonstrate a clear connection between water pressure and speed. Iken (1977) found diurnal variations in speed on Findelengletscher.

On Storglaciären, as on Findelengletscher and Unteraargletscher, the velocity peaks are related to local weather conditions that affect water input to the glacier. High water inputs may result in high basal water pressures at any time during the melt season. They are particularly effective early in the season before the glacier-drainage system has developed. High water pressures early in the melt season usually result in increases in velocity; those occurring later in the season may or may not coincide with velocity increases. In the latter case, the water pressures measured may not be representative of conditions under the glacier as a whole.

In areas where Storglaciären rests on bedrock, high water pressures probably result in a combination of increased separation and hydraulic jacking, and hence the increase in velocity. Elsewhere, particularly in the overdeepening, the accelerations are presumably due to a decrease in drag resulting from a decrease in effective normal pressure in a subglacial till layer. At any one location on the glacier, however, changes in velocity are likely to be strongly dependent upon changes at the bed in locations some distance away, transmitted by longitudinal stresses. 
Comparison of vertical velocities and surface strainrates in the five strain diamonds on Storglaciären suggests that $\left|\dot{\varepsilon}_{z z}\right|$ decreases with depth near the surface of the glacier. At greater depths, $\left|\dot{\varepsilon}_{z z}\right|$ may, in some instances, become zero and then begin to increase again.

Changes in vertical velocity suggest corresponding changes in the depth dependence of $\dot{\varepsilon}_{z z}$. Noteworthy is the observation that the most prominent variations occur on a seasonal time-scale rather than on the shorter time-scales of the weather-related changes in horizontal velocity. In the overdeepening, it appears that during the late summer both $\dot{\varepsilon}_{z z}$ and $\dot{\varepsilon}_{y y}$ become more compressive beneath the center of the glacier. Conversely, down-glacier from the riegel, $\dot{\varepsilon}_{\text {yy }}$ may become more extending during the summer.

\section{ACKNOWLEDGEMENTS}

This study was supported by grants from the U.S. National Science Foundation (grants DPP-8414190 and DPP-8619086) and the Swedish Natural Science Research Council. The base of operations was the Tarfala Field Station which is maintained by the Building Authority of the Swedish Government. Important items of permanent equipment used in the work were bought with funds provided by the Wallenberg Foundation.

For their efforts to make Tarfala an especially pleasant and well-maintained field station at various times during this project, we gratefully acknowledge the efforts of B. Bachman, A. Hooke, G. Johansson, E. Person, K. Reece, and Anna Nora Schytt. For conducting the surveys, of ten under unpleasant weather conditions to say the least, we warmly acknowledge the assistance of the many Swedish and American students, as well as those from other lands, who have participated in the program over the years. $K$. Brugger, J. Brzozowski, and K. Erickson deserve special mention for their efforts.

Discussions with V. Pohjola, R. Walters, and particularly W. Harrison sharpened our thinking on some of the problems discussed. The critical reviews of $\mathrm{K}$. Echelmeyer, W. Harrison, A. Iken, C. Raymond, and I. Whillans resulted in substantial improvements in the paper.

We dedicate this paper to the memory of Valter Schytt, close friend, stimulating colleague, and enthusiastic supporter, whose personal efforts and vision over 40 years resulted in the present research station at Tarfala.

\section{REFERENCES}

Alley, R.B., D.D. Blankenship, C.R. Bentley, and S.T. Rooney. 1987. Till beneath Ice Stream B. 3. Till deformation: evidence and implications. J. Geophys. Res., 92(B9), 8921-8929.

Bindschadler, R. 1983. The importance of pressurized subglacial water in separation and sliding at the glacier bed. J. Glaciol., 29(101), 3-19.

Björnsson, H. 1981. Radio-echo sounding maps of Storglaciären, Isfallsglaciären, and Rabots glaciär, northern Sweden. Geogr. Ann., 63A(3-4), 225-231.

Brand, G., V. Pohjola, and R.LeB. Hooke. 1987. Evidence for a till layer beneath Storglaciären, Sweden, based on electrical resistivity measurements. J. Glaciol., 33(115), 311-314.

Clarke, G.K.C. 1987. Subglacial till: a physical framework for its properties and processes. J. Geophys. Res., 92(B9), 9023-9036.

Harrison, W.D. 1975. A measurement of surfaceperpendicular strain-rate in a glacier. J. Glaciol., 14(70), 31-37.

Hodge, S.M. 1974. Variations in the sliding of a temperate glacier. J. Glaciol., 13(69), 349-369.

Holmlund, P. 1988. Internal geometry and evolution of moulins, Storglaciären, Sweden. J. Glaciol., 34(117), 242-248.

Holmlund, P. and R.LeB. Hooke. 1983. High waterpressure events in moulins, Storglaciären, Sweden. Geogr. Ann., 65A(1-2), 19-25.
Hooke, R.LeB., J.E. Gould, and J. Brzozowski. 1983a. Near-surface temperatures near and below the equilibrium line on polar and subpolar glaciers. Z. Gletscherkd. Glazialgeol., 19(1), 1-25.

Hooke, R.LeB., J. Brzozowski, and C. Bronge. 1983b. Seasonal variations in surface velocity, Storglaciären, Sweden. Geogr. Ann., 65A(3-4), 263-277.

Hooke, R.LeB., P. Holmlund, and N.R. Iverson. 1987. Extrusion flow demonstrated by bore-hole deformation measurements over a riegel, Storglaciären, Sweden. J. Glaciol., 33(113), 72-78.

Hooke, R.LeB., S.B. Miller, and J. Kohler. 1988. Character of the englacial and subglacial drainage system in the upper part of the ablation area of Storglaciären, Sweden. J. Glaciol., 34(117), 228-231.

Iken, A. 1978. Variations of surface velocities of some Alpine glaciers measured at intervals of a few hours. Comparison with Arctic glaciers. Z. Gletscherkd. Glazialgeol., 13(1/2), 1977, 23-35.

Iken, A. 1981. The effect of the subglacial water pressure on the sliding velocity of a glacier in an idealized numerical model. J. Glaciol., 27(97), 407-421.

Iken, A. and R.A. Bindschadler. 1986. Combined measurements of subglacial water pressure and surface velocity of Findelengletscher, Switzerland: conclusions about drainage system and sliding mechanism. J. Glaciol., 32(110), 101-119.

Iken, A., R.H. Flotron, W. Haeberli, and H. Röthlisberger. 1983. The uplift of Unteraargletscher at the beginning of the melt season - a consequence of water storage at the bed? J. Glaciol., 29(101), 28-47.

Jaeger, J.C. 1969. Elasticity, fracture and flow. Third edition. London, Methuen.

Jones, A.S. 1979. The flow of ice over a till bed. $J$. Glaciol., 22(87), 393-395.

Kamb, W.B. 1970. Sliding motion of glaciers; theory and observation. Rev. Geophys. Space Phys., 8(4), 673-728.

$\mathrm{Kamb}, \mathrm{B}$. , and seven others. 1985. Glacier surge mechanism: 1982-1983 surge of Variegated Glacier, Alaska. Science, 227(4686), 469-479.

Lliboutry, L. 1979. Local friction laws for glaciers: a critical review and new openings. J. Glaciol., 23(89), 67-95.

Nye, J.F. 1952. The mechanics of glacier flow. J. Glaciol., 2(12), 82-93.

Östling, M. and R. LeB. Hooke. 1986. Water storage in Storglaciären, Kebnekaise, Sweden. Geogr. Ann., 68A(4), 279-290.

Raymond, C.F. 1971. Flow in a transverse section of Athabasca Glacier, Alberta, Canada. J. Glaciol., 10(58), 55-84.

Rydén, A. Unpublished. Horisontalspänningar och hastigheter i en glaciärs ytskikt. (C-uppsats i Naturgeografi, Uppsala Universitet, 1988.)

Schytt, V. 1966. Notes on glaciological activities in Kebnekaise, Sweden during 1965. Geogr. Ann., 48A(1), 43-50.

Schytt, V. 1968. Notes on glaciological activities in Kebnekaise, Sweden during 1966 and 1967. Geogr. Ann., $50 \mathrm{~A}(2), 111-120$.

Seaberg, S.Z., J.Z. Seaberg, R.LeB. Hooke, and D.W. Wiberg. 1988. Character of the englacial and subglacial drainage system in the lower part of the ablation area of Storglaciären, Sweden, as revealed by dye-trace studies. $J$. Glaciol., 34(117), 217-227.

Van der Veen, C.J. and I.M. Whillans. 1989. Force budget: I. Theory and numerical methods. J. Glaciol., 35(119), 53-60.

\section{APPENDIX I}

\section{UNCERTAINTY IN VELOCITY MEASUREMENTS}

The standard error in the Geodimeter measurements is $\pm(5 \mathrm{~mm}+10 \mathrm{ppm})$, assuming that the temperature and pressure used for the $\mathrm{P}-\mathrm{T}$ corrections are representative of those on the glacier at the time of measurement. The median distance between a stake and the fixed points used for determining its position was $850 \mathrm{~m}$ so the standard error in these distances is $\pm 14 \mathrm{~mm}$. For the longest distance 
measured, $1900 \mathrm{~m}$, the standard error is $\pm 24 \mathrm{~mm}$. Because all measurements were made with the same Geodimeter, however, the uncertainty in changes in position is less than would be suggested by using these standard errors and applying normal rules of error propagation. An analysis carried out earlier (Hooke and others, 1983b), based on the assumption that strain-rates varied smoothly over distances of $\sim 200 \mathrm{~m}$, gave an uncertainty of $\pm 12 \mathrm{~mm}$ in successive positions of stakes about $750 \mathrm{~m}$ from the fixed points, suggesting a standard error of $\sim \pm 10 \mathrm{ppm}$ in a single position calculation. As derived, this figure applies strictly to the positions of the bottoms of the stakes but, because changes in lean between surveys in the earlier study were small, we conservatively apply it to the stake tops in the present study.

The lean corrections introduced additional error, particularly when stakes became bent due to snow pressure. Such bending occurred because the junctions between the stakes and the extensions which were added during the winter were not completely rigid. In these cases a "compound lean correction" was used. To make this correction, the average inclination of the stake was determined at two different times when it was the same length, let us say $4 \mathrm{~m}$ for purposes of illustration. This $4 \mathrm{~m}$ stake might consist of a bottom part $2 \mathrm{~m}$ long and two $1 \mathrm{~m}$ extensions. Linear interpolation or extrapolation was then used to obtain average inclinations at other times. Lean measurements on one or more $1 \mathrm{~m}$ extensions on top of this $4 \mathrm{~m}$ stake could then be used to calculate the mean lean of the entire stake. This procedure involved the following assumptions: (a) all bending occurred at junctions between extensions; (b) an inclination measurement made on an extension applied only to that extension; (c) the change in inclination of the lower part of the stake was linear in time, thus permitting calculation of its lean when it was buried; and (d) when inclination data were not available on certain extensions but were available on higher extensions which had been measured and on lower parts of the stake based on assumption (c) above, the bending was assumed to be distributed equally among the junctions.

When changes in mean lean between successive surveys were relatively large, as was of ten the case when a bent stake was extended or shortened, these procedures introduce considerable uncertainty into the calculation of the position of the bottom of the stake relative to the measured position of the top. An inclination error of $1^{\circ}$ would result in an error of $87 \mathrm{~mm}$ in a stake $5 \mathrm{~m}$ long. For most stakes most of the time, the rate of change in the mean inclination was less than $0.02 \%$ and the error in our estimate of this rate of change is probably half that, so the resulting standard error in horizontal velocity from this source is estimated to be $\pm 1 \mathrm{~mm} / \mathrm{d}$. The errors are generally larger than this in the accumulation area, particularly in the spring when there were of ten several extensions on the stakes, pressures due to snow creep were large, and changes in pressure due to melting were also large.

Another factor influencing the accuracy of the stake coordinates is the horizontal angle between the vectors to the two fixed points used to determine the location of the stake. While most of these angles were between $\sim 70^{\circ}$ and $\sim 110^{\circ}$, the smallest angles are as small as $38^{\circ}$ and the largest reach $136^{\circ}$. In these instances, the uncertainty in the coordinates is different in the two coordinate directions, and uncertainty in either the magnitude or the azimuth of velocity vector is affected accordingly.
Vertical angles were measured to the nearest $0.0001^{\mathrm{y}}$ and were normally reproducible to $\pm 0.0010^{\mathrm{g}}$. As each angle was normally measured twice, this implies a standard error in the mean of $\pm 0.0005 \mathrm{~g}$. The resulting uncertainty in vertical coordinate is $\pm 15 \mathrm{~mm}$ for the most distant stake. No corrections were made for variations in refraction during or between surveys; this could result in an additional systematic error in velocity of comparable magnitude.

Such analyses do not take into consideration the occasional larger operator errors that invariably occur, particularly in a series of measurements carried out by many different people over so long a period of time. To identify and eliminate at least the worst of these, computer-generated "staircase" plots of velocity against time, similar to those in Figure 3, were prepared for each stake. Large oscillations in velocity from one survey period to the next that could be attributed to an error in the survey between the two periods were checked, as were situations in which nearby stakes revealed distinctly different patterns. Often errors were found that could be corrected or that provided a rational basis for discarding data. Sometimes the irregularity occurred at times when a stake was cut or extended, suggesting an error in the lean calculated by linear interpolation. Less frequently some velocities appeared to be so unrealistic in comparison with other evidence that data were discarded without clearly identifying the source of the error. In such cases, velocities were averaged over two or more measuring periods.

\section{APPENDIX II}

\section{CALCULATION OF VELOCITY DERIVATIVES FOR FORCE-BALANCE ANALYSIS}

For the larger of the two blocks studied, that in the overdeepening (Fig. 1), the procedure for obtaining velocity derivatives was as follows:

$\partial u / \partial x, \partial v / \partial y, \partial v / \partial x$. At the up-glacier end of the block, a hypothetical stake having a velocity equal to the mean of the velocities of stakes $198_{2}$ and $198_{3}$ was compared with stake 188 (Fig. 1). At the down-glacier end, a similar calculation was made for stake 3.35 and a hypothetical stake in the middle of the 2 line. To calculate $\dot{\varepsilon}_{\mathrm{e}}$ in the second of Equations (4), the mean of the values of $\partial u / \partial x$ at the up-glacier and down-glacier ends of the block was assumed to apply in the middle of the block, and similarly for $\partial v / \partial y$.

$\partial u / \partial y$. Along the sides of the block, the average of the values of $\partial u / \partial y$ calculated from stakes $198_{1}$ and $198_{2}$, and from 2.1 and 2.25 was used on the south side, and a similar average obtained from stakes $198_{3}, 198_{4}, 2.45$, and $2 \mathrm{~N}$ was used on the north side. For estimating $\dot{\varepsilon}_{\mathrm{e}}$ at the up-glacier and down-glacier ends of the block, $\partial u / \partial y$ was also obtained from stakes $198_{2}$ and $198_{3}$, and from 2.25 and 2.45 , respectively.

For the smaller block, $\partial u / \partial x$ was determined from stakes 07 and 05 at the up-glacier end, and stakes 03 and 02 at the down-glacier end. $\partial u / \partial y$ was determined from the average of the values between stakes $03_{1}$ and $03_{2}$ and between $03_{2}$ and 03 on the south side, and similarly, using stakes 03 through $03_{4}$, on the north side. Otherwise, the procedure was the same as for the larger block. 